\title{
Perbaikan Sistem Kerja Proses Pemasangan Ban Truk dengan Perancangan Peralatan Pendukung Menggunakan QFD dan REBA
}

\author{
Hery Hamdi Azwir ${ }^{1}$, Farhan Kusniadi Putra ${ }^{2}$, Hirawati Oemar ${ }^{3}$ \\ 1,2)Industrial Engineering Department, President University, Jababeka, Cikarang, Bekasi 17530 \\ 3) Fakultas Teknik, Teknik Industri, Universitas Islam Bandung, Bandung 40116 \\ Email: ${ }^{1}$ hery.azwir@president.ac.id, ${ }^{2}$ hans_farhanskusniadi@yahoo.com, ${ }^{3}$ hirawatio@yahoo.co.id
}

\begin{abstract}
PT.X as one of the heavy equipment manufacturing company are producing mining and non-mining transportation product (e.g. Semi Side Tipper (SST) \& Dolly). In producing those kinds of products that mostly using tires, there is a process area to do mounting truck tire. Based on interviews and direct observation results, there is a symptom of Cumulative Trauma Disorders (CTD), especially in the low back area. The low back pain experienced by the operators is caused by an awkward posture that resulted from Manual Material Handling (MMH) in this process. Lifting and holding the tire that is located on the floor with diameter $1.2 \mathrm{~m}$, height $0.3 \mathrm{~m}$, and weight $90 \mathrm{Kg}$ also the reasons why the awkward posture appears during the mounting truck tire process. Using Rapid Entire Body Assessment (REBA), Nordic Questionnaire, and followed by the Quality Function Deployment (QFD) approach for product design are used to do the improvement for the process. In the end, these ergonomics issues are solved by developing material handling tools that can minimize the risk and symptoms of CTDs. It can be shown by initially REBA score is on level 11 (Very High Risk) to level 7 (Medium Risk) and for the Nordic result from 7 body parts that feel discomfort, now it just becomes 1 body parts feel discomfort.
\end{abstract}

Keywords: cumulative trauma disorder, ergonomics, low back pain, nordic questionnaire, quality function deployment (QFD), rapid entire body assessment (REBA)

\begin{abstract}
Abstrak
PT.X adalah salah satu perusahaan manufaktur alat berat yang memproduksi produk transportasi pertambangan dan non pertambangan (misalnya Semi Side Tipper (SST) \& Dolly). Dalam memproduksi produk tersebut cukup banyak ban yang digunakan, sehingga terdapat area khusus untuk proses pemasangan ban truk. Berdasarkan hasil wawancara dan observasi langsung di area tersebut didapatkan adanya keluhan gejala gangguan trauma kumulatif (CTD) khususnya pada daerah punggung bawah. Sakit punggung bawah yang dialami oleh operator disebabkan oleh postur tubuh yang canggung akibat penanganan material masih secara manual. Mengangkat dan menahan ban yang terletak di lantai berdiameter $1.2 \mathrm{~m}$, tinggi $0.3 \mathrm{~m}$ dan berat $90 \mathrm{Kg}$ juga menjadi alasan munculnya postur canggung saat proses pemasangan ban truk. Untuk melakukan perbaikan pada proses ini dilakukan analisis dengan menggunakan Rapid Entire Body Assessment (REBA), Nordic Questionnaire, dan dilanjutkan dengan desain produk menggunakan pendekatan Quality Function Deployment (QFD). Produk yang dihasilkan adalah sebuah alat bantu untuk material handling yang dapat mengurangi secara signifikan terjadinya CTD. Pada akhirnya masalah ergonomi ini teratasi, dan resiko serta gejala CTD berkurang yang ditunjukkan dari skor REBA yang semula berada pada level 11 (berisiko bangat tinggi) menjadi level 7 (berisiko sedang) dan untuk hasil Nordic dari 7 bagian tubuh yang merasa tidak nyaman, kemudian hanya menjadi 1 bagian tubuh yang terasa tidak nyaman.
\end{abstract}

Keywords: cumulative trauma disorder, ergonomics, low back pain, nordic questionnaire, quality function deployment (QFD), rapid entire body assessment (REBA) 


\section{Pendahuluan}

Dalam dunia industri manufaktur alat berat secara umum, PT. $X$ adalah salah satu perusahaan terkemuka di Indonesia. Bidang usahanya difokuskan pada produsen alat berat hasil tambang dan non-pertambangan. Perusahaan ini hanya memproduksi peralatan tambahan alat berat (heavy equipment attachment) selain prime mover atau head truck. Dua attachment alat berat yang diproduksi perusahaan adalah Semitrailer Side Tipper (SST 74) dan Dolly 50. Gambar 1 menunjukkan kendaraan SST 74 dan Dolly 50 tersebut.

SST 74 merupakan produk angkutan pertambangan yang menangani material curah dan pengangkutan batubara, bauksit, bijih besi, dan lain-lain untuk jarak jauh. Sedangkan Dolly 50 memiliki fungsi utama sebagai 'joint' untuk menghubungkan satu trailer dengan yang lain sehingga menjadi fungsi trailer yang panjang dan lebih efisien dari sisi bisnis. Dalam proses produksi kedua produk tersebut, perusahaan memiliki lini produksi produk Trailer sendiri, mulai dari proses pemasangan ban, fabrikasi material, perakitan, hingga pemeriksaan produk yang semua dilakukan oleh perusahaan.

Dari seluruh proses produksi untuk pembuatan trailer, diawalnya selalu terdapat proses pemasangan ban TBR (Truck Bus Radial). Ban trailer yang juga menggunakan ban TBR memiliki tujuan utama untuk menopang beban kendaraan dan juga beban dari barang yang diangkut oleh SST selama bertugas sebagai angkutan pertambangan. Pada tahun 2014, ban 2528 TBR dipasang dengan proses mount ban truk untuk memenuhi kebutuhan 12 TBR SST 74 dan 8 TBR Dolly 50. Banyaknya TBR yang dihasilkan pada tahun tersebut menunjukkan adanya permintaan yang tinggi untuk proses pemasangan ban truk.
Saat melakukan pengamatan di area pemasangan ban, sebagian besar proses masih ditangani oleh operator secara Manual Material Handling (MMH). Selama pengamatan, masih terlihat postur tubuh yang kurang tepat oleh operator terutama di area menekuk punggung atau badan ke depan untuk mengangkat ban / alat dari lantai. Proses pemasangan ban truk ini tidak mungkin dilakukan oleh satu operator karena jika terdapat kendala dalam pemasangan ban maka operator akan meminta bantuan operator lain yang bekerja di area tersebut.

Dalam satu hari, area pemasangan ban (mounting tire) mampu mengerjakan hingga 15 kali pemasangan perhari dan membutuhkan minimal 3-operator untuk mendukung aktifitas yang dilakukan. Dalam setiap ban TBR yang dipasang pada proses ini, jumlah posisi tidak benar (canggung) yang ditunjukkan oleh operator (menekuk bagian belakang) hingga mengangkat dan menahan ban, paling sedikit 5 kali / ban. Jika satu ban membutuhkan 5-kali postur canggung oleh operator, artinya operator harus melakukan postur canggung hingga 25 kali / hari masing-masing atau menjadi total 75 kali / hari.

Postur canggung yang ditunjukkan oleh operator menunjukkan ada yang tidak beres dengan proses dan perlu perbaikan untuk meminimalkan jumlah postur canggung yang dilakukan oleh operator. Jika postur canggung seperti ini terjadi setiap hari, operator dapat terkena gangguan trauma kumulatif (CTDs). Operator merasakan ketidaknyamanan di tangan, pergelangan tangan, serta punggung atas dan bawah setelah melakukan proses pemasangan ban. Hal ini menyebabkan terjadinya gejala gangguan muskuloskeletal dan sistem saraf.

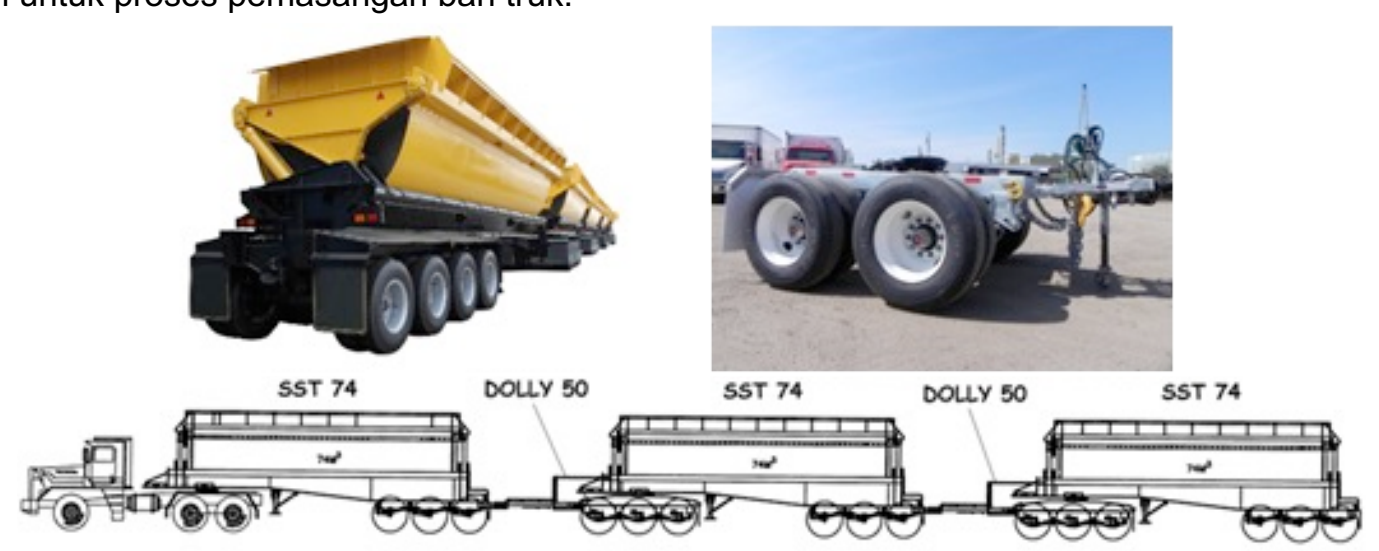

Gambar 1. Semitrailer side tipper (Kiri), dolly (Kanan) and on-road arrangement (Bawah) 
Ergonomi adalah ilmu yang memperhatikan 'kesesuaian' antara manusia dan pekerjaan mereka. Dengan memasukkan manusia / operator di posisi pertama, maka area kerja harus aman, nyaman, dan efektif untuk mendukung produktivitas yang lebih baik (Christy, 2019). Ilmu ergonomi memiliki tujuan untuk memastikan alat kerja, tugas, peralatan, informasi, dan lingkungan sesuai dengan setiap pekerja (Berlin et al., 2017).

Ergonomi juga adalah IImu yang merupakan bagian integral dari desain, manufaktur, dan kebutuhan manusia disebut. Mengetahui bagaimana studi antropometri, postur, gerakan berulang, dan desain ruang kerja mempengaruhi pengguna secara kritis untuk pemahaman yang lebih baik tentang ergonomi yang berkaitan dengan kebutuhan pengguna akhir (Shorrock \& Williams, 2016).

Banyak penelitian yang telah dilakukan pada kasus gangguan trauma kumulatif (CTD) dan manual material handling ( $\mathrm{MMH})$, diantaranya adalah (Kosasih et al., 2019), menggunakan metode REBA dan WSC untuk liquid container, (Wahyuniardi \& Reyhanandar, 2018), menggunakan Metode REBA dan RULA pada industri manufaktur PJU, (Theopilus et al., 2018), menggunakan metode NIOSH, RULA, dan NASA-TLX untuk industri crank case, (Fitriani \& Purnomo, 2018), menggunakan QFD untuk desain produk bed shower pasien dengan mempertimbangkan konsep ergonomis, (Sari et al., 2017), menggunakan Metode QEC di industri furnitur, (Bintang \& Dewi, 2017) menggunakan OWAS dan RULA di gudang gula, (Haripurna \& Purnomo, 2017) menggunakan metode MEAD di industri gula, dan (López-Aragón et al., 2017) menggunakan NMQ.

Proses pemasangan ban saat ini memerlukan beberapa perbaikan agar operator dapat bekerja lebih mudah, aman, efektif, dan efisien di masa mendatang. Penelitian ini bertujuan untuk merancang dan mengembangkan peralatan pendukung untuk meminimalkan risiko Cumulative Trauma Disorder (CTD) pada area punggung bawah untuk proses pemasangan ban truk oleh operator. Metode yang diterapkan adalah REBA dan NMQ untuk analisis postur dan QFD untuk merealisasikan desain produk. Metode ini dipilih karena tidak mengharuskan penggunaan peralatan khusus untuk analisis ergonomi yang menjadi tambahan biaya bagi perusahaan dan sangat sesuai dengan kasus yang dihadapi, juga tidak terlalu membutuhkan skill yang tinggi untuk mengaplikasikannya. Hasil dari penelitian ini diharapkan dapat memunculkan ide bagi kalangan industri terkait tentang bagaimana merancang dan membangun produk alat bantu pemasangan ban berukuran besar yang cukup efektif namun low-cost.

\section{Metodologi}

Secara umum penelitian dilakukan dengan (1) melakukan observasi terhadap aktifitas pemasangan ban, (2) melakukan analisis REBA awal terhadap postur tubuh saat aktivitas tersebut dilakukan dan pengisian kuesioner Nordic sehingga mendapatkan informasi level risiko dan prosentasi bagian tubuh yang mengalami ketidaknyamanan, (3) setelah didapat informasi tersebut selanjutnya merancang dan mengembangkan alat bantu yang dapat menurunkan tingkat risiko dan juga menurunkan prosentasi jumlah bagian tubuh yang tidak nyaman semuanya ke tingkat yang masih dapat diterima; untuk mendesain alat tersebut maka QFD digunakan, (4) setelah alat bantu tersebut direalisasikan maka dilakukan analisis kembali melalui analisi REBA dan kuesioner Nordic untuk memastikan bahwa risiko dan jumlah bagian tubuh yang tidak nyaman telah menurun ke tingkat yang masih dapat diterima.

\section{Rapid Entire Body Assessment (REBA)}

REBA adalah alat bantu penilaian ergonomi tanpa memerlukan peralatan ergonomi yang canggih dan mahal, namun cukup dengan hanya pena, lembar kerja REBA, dan kamera (Hignett \& McAtamney, 2000).

Lembar kerja REBA mengevaluasi dan menetapkan skor untuk masing-masing bagian tubuh berikut ini: (1) pergelangan tangan, (2) lengan bawah, (3) bahu, (4) leher, (5) lutut, (6) kaki dan batang.

Setelah data dikumpulkan dan diberi skor, selanjutnya tabel pada lembar kerja akan menentukan level faktor risiko, menghasilkan skor tunggal yang merepresentasikan tingkat risiko MSD (Middlesworth, 2014). Tabel 1. Menunjukkan tingkat REBA dari Risiko MSD.

Skor REBA dapat ditentukan dengan menganalisis proses objek. Disini yang diamati adalah pergerakan, postur tubuh, dan aktivitas operator. Analisis dapat dilakukan dengan 
observasi langsung ke lapangan dan melihat aktivitas pekerja dalam beberapa siklus kerja. Proses dan aktivitas yang harus dianalisis dan dievaluasi didasarkan pada:

1. Postur dan tugas yang paling sulit dari para pekerja dalam melakukan pekerjaan. Itu bisa dilakukan dengan wawancara pekerja dan observasi langsung.

2. Postur tubuh yang dipertahankan dalam jangka waktu lama dan / atau tingkat tinggi dari proses kerja yang berulang.

3. Postur tubuh dimana operator melakukan gaya yang berlebihan pada tubuh operator

Tabel 1. Level MSD risk

\begin{tabular}{|c|l|}
\hline Score & Level of MSD risk \\
\hline $\mathbf{1}$ & Negligible risk, no action required \\
\hline $\mathbf{2 - 3}$ & Low risk, change may be needed \\
\hline $\mathbf{4 - 7}$ & $\begin{array}{l}\text { Medium risk, further investigation, } \\
\text { change soon }\end{array}$ \\
\hline $\mathbf{8 - 1 0}$ & $\begin{array}{l}\text { High risk, investigate and } \\
\text { implement the change }\end{array}$ \\
\hline Score & Level of MSD Risk \\
\hline
\end{tabular}

\section{Kuesioner Muskuloskeletal Nordik}

Kueisioner Nordik merupakan salah satu alat untuk mengukur distress muskuloskeletal. Instrumen ini dapat digunakan untuk menilai tingkat ketidaknyamanan secara umum di seluruh pekerjaan, terlepas dari sumber rasa sakit. Bentuk umum kuesioner Nordik dirancang oleh Institute of Occupational Health di negaranegara Nordik. Beberapa alat bantu telah digunakan secara luas dan teruji di Denmark, Finlandia, Norwegia, Swedia, dan Inggris. Hasil kuesioner Nordik dapat disajikan dengan berbagai cara. Evaluasi kelompok kerja berdasarkan jumlah bagian tubuh yang dilaporkan dan jumlah ketidaknyamanan di bagian tubuh yang serupa (Crawford, 2007). Gambar 2 menunjukkan contoh Kuesioner Nordik

\section{Quality Function Deployment (QFD)}

Quality Function Deployment adalah suatu metode perancangan produk atau layanan berdasarkan keinginan pelanggan yang melibatkan seluruh anggota organisasi produsen atau pemasok (Fitriani \& Purnomo, 2018). Dalam bahasa Jepang, 'deployment' mengacu pada kegiatan perluasan yang artinya untuk menghasilkan produk yang berkualitas harus melibatkan banyak orang yang terkait.

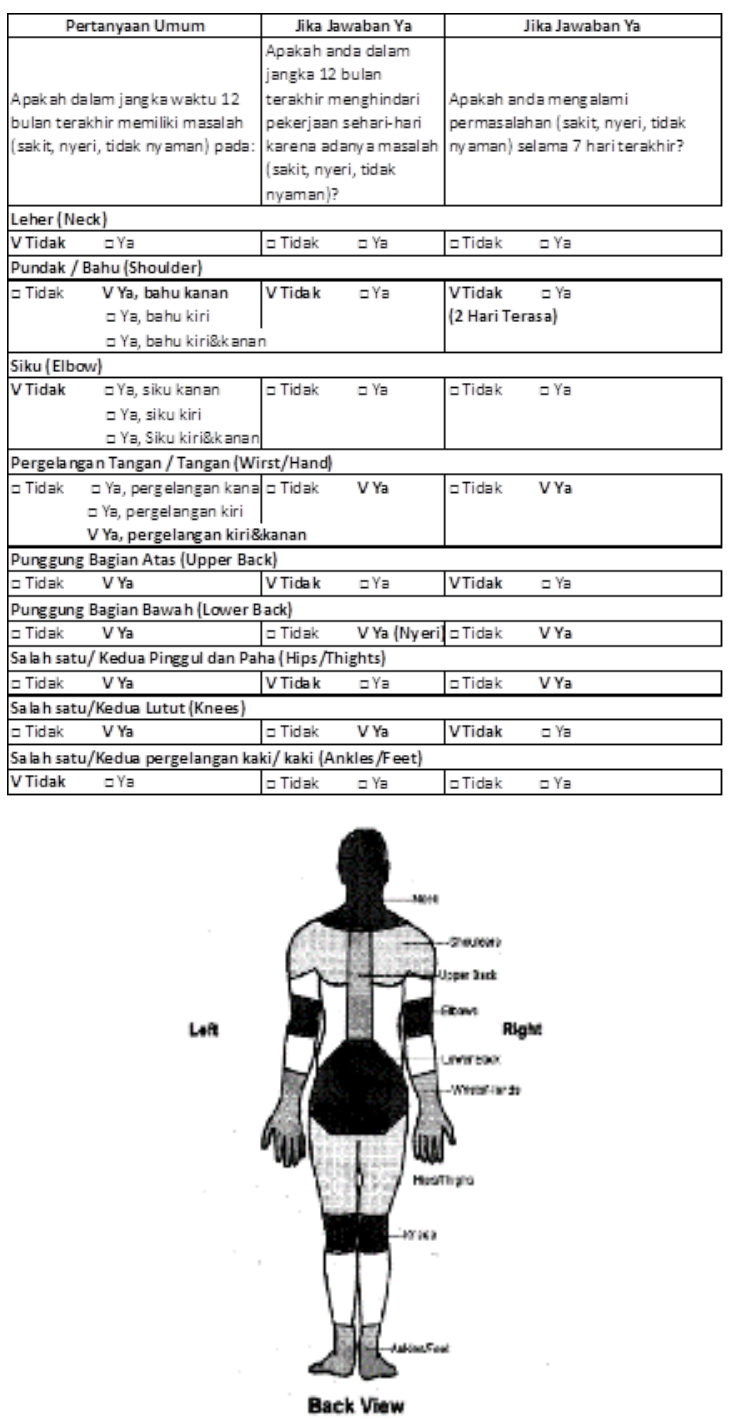

Gambar 2. Standarisasi kuesioner nordik

QFD adalah metode untuk mengembangkan mutu desain yang bertujuan untuk memuaskan customer dengan cara menerjemahkan permintaan atau kebutuhan customer ke dalam target desain dan menjadi titik jaminan kualitas utama untuk digunakan selama fase produksi. QFD adalah salah satu cara untuk memastikan kualitas desain saat produk masih dalam tahap desain.

Pada implementasi Quality Function Deployment, terdapat 3 tujuan utama:

1. Memprioritaskan keinginan atau kebutuhan customer baik yang terucap maupun tidak.

2. Mengubah keinginan atau kebutuhan ini menjadi suatu karakteristik dan spesifikasi teknis. 
3. Mengembangkan produk atau layanan bermutu dengan berfokus pada kepuasan customer.

Bagian akhir dari QFD adalah membuat apa yang disebut sebagai rumah kualitas (House of Quality). Ada 8 langkah untuk membangun House of Quality:

Langkah-1: Mengidentifikasi pelanggan: Siapa mereka? Pelanggan terpenting adalah konsumen, yaitu orang yang akan membeli dan menggunakan produk.

Langkah-2: Tentukan tuntutan pelanggan: Apa yang diinginkan pelanggan? Mendapatkan suara pelanggan ( $\mathrm{VoC}$ ), mengetahui dengan tepat apa yang mereka inginkan dan butuhkan dalam produk. Cara mengumpulkan VoC secara umum adalah melalui observasi, survei, atau FGD.

Langkah-3: Tentukan kepentingan relatif dari tuntutan: Siapa versus apa pada bagian ini, pelanggan harus memberikan bobot dari setiap tuntutan pelanggan yang telah mereka tentukan sendiri sebelumny dan total bobot adalah $100 \%$.

Langkah-4: Identifikasi dan evaluasi persaingan: Seberapa puas pelanggan sekarang? Bagian ini disebut benchmarking persaingan, setiap produk yang bersaing harus dibandingkan dengan kebutuhan atau pelanggan.

Langkah-5: Hasilkan spesifikasi teknik: Bagaimana tuntutan pelanggan akan dipenuhi? Menerjemahkan tuntutan pelanggan ke dalam beberapa spesifikasi teknik yang akan memenuhi harapan mereka. Disini suara pelanggan menjadi suara insinyur. Pada saat yang sama, desainer menentukan arah perbaikan (minimalkan, maksimalkan, atau target).

Langkah-6: Hubungkan tuntutan pelanggan dengan spesifikasi teknik: Bagaimana mengukur apa? Setelah menentukan kebutuhan pelanggan dan spesifikasi teknik dari produk, jenis hubungan yang mungkin terkait dengan tuntutan pelanggan dan spesifikasi teknik dijelaskan dalam gambar.

Langkah-7: Tetapkan target spesifikasi teknik dan kepentingan: Seberapa banyak yang cukup baik? Tujuan dari langkah-langkah tersebut adalah untuk mengetahui tingkat kepentingan masing-masing spesifikasi teknik yang sudah dibuat oleh desainer sehingga dapat mengetahui spesifikasi mana yang harus lebih didahulukan untuk mencapai kebutuhan pelanggan.

Langkah-8: Atap, Identifikasi hubungan antara spesifikasi teknik: Bagaimana ketergantungan satu sama lain? Setiap spesifikasi teknik mungkin memiliki keterkaitan satu sama lain dan mungkin bergantung satu sama lain.

\section{Hasil dan Diskusi}

\section{Analisis Postur Tubuh REBA - Awal}

Proses analisis REBA awal untuk untuk mengetahui kondisi awal dapat diperlihatkan dalam Gambar 3, yaitu analisis postur operator dan mengkonversikannya ke dalam template penilaian REBA. Hasilnya didapatkan nilai REBA awal sebesar 11, dan berdasarkan Tabel 1 artinya proses pemasangan ban truk berada pada level risiko sangat tinggi sehingga perlu segera dilakukan perbaikan.

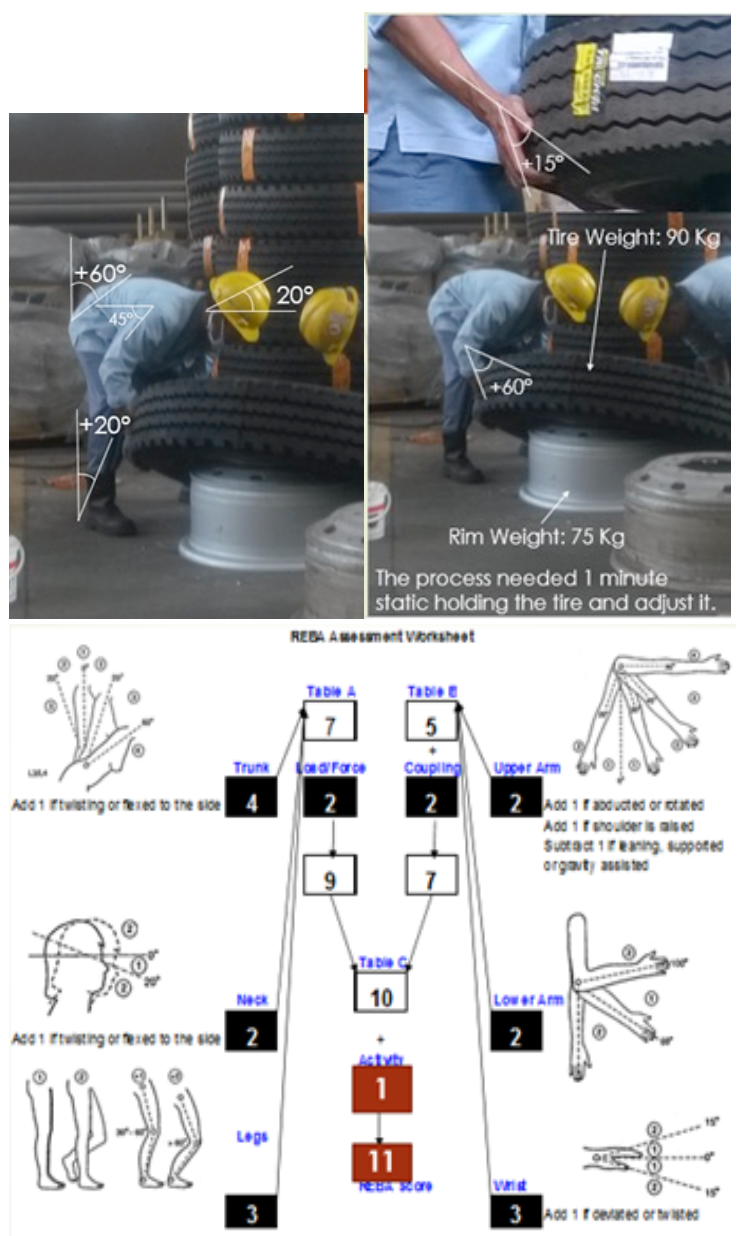

Gambar 3. Gambar ringkasan REBA awal

Berdasarkan skor REBA awal, maka jika dianalisis lebih lanjut, dapat ditemukan beberapa proses yang tidak ergonomis: 
- Operator menggunakan tenaga yang sangat besar untuk mengangkat dan menangani ban truk. Dengan mempertimbangkan ukuran ban berdiameter $120 \mathrm{~cm}$ dengan tinggi $30 \mathrm{~cm}$ dan berat $90 \mathrm{Kg}$ dapat dipahami bahwa proses ini membutuhkan tenaga besar dari operator untuk menanganinya (Manual Material Handling).

- Postur canggung yang ditimbulkan dari proses ini membuat operator menderita karena operator harus menangani ban truk tersebut dengan mempertahankan postur yang canggung tersebut. Apalagi jika operator sedang membungkuk untuk mencapai objek di lantai saat operator dalam posisi berdiri.

\section{Analisis Kondisi Tubuh Kuesioner Nordik - Awal}

Salah satu bagian tubuh yang terasa tidak nyaman dan perlu diperhatikan adalah area punggung bawah. Situasi tersebut dapat dilihat pada Gambar 4. Selanjutnya penilaian postur kerja dan tubuh dilakukan dengan kuesioner Nordic yang memberikan informasi bahwa kondisi umum operator $A$ setelah melakukan proses pemasangan ban truk perlu diperbaiki. Ditemukan bahwa terdapat 7 dari 9 bagian tubuh $(77.7 \%)$ sebagaimana diperlihatkan dalam Gambar 5. yang menunjukkan adanya ketidaknyamanan setelah proses pemasangan ban truk.

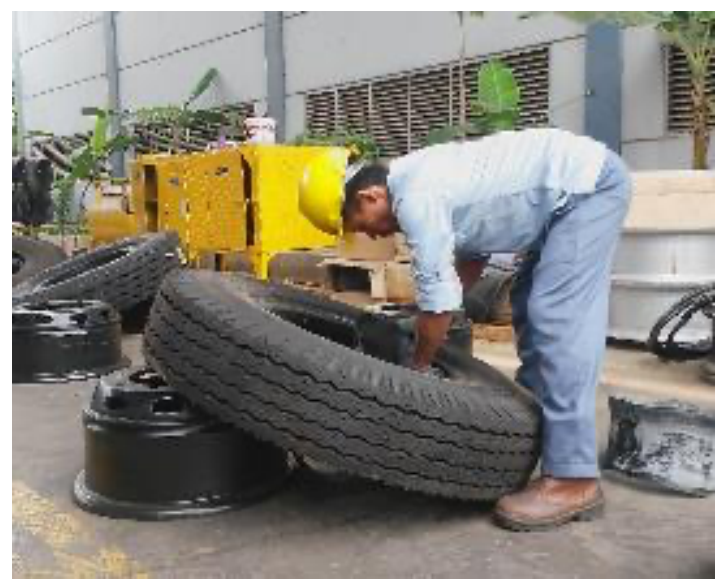

Gambar 4. Operator A memasukkan flap

Dari setiap poin kebutuhan pelanggan, dilanjutkan dengan melakukan analisis dan berusaha menjawab setiap poin kebutuhan mereka. Di bawah ini adalah terjemahan dari

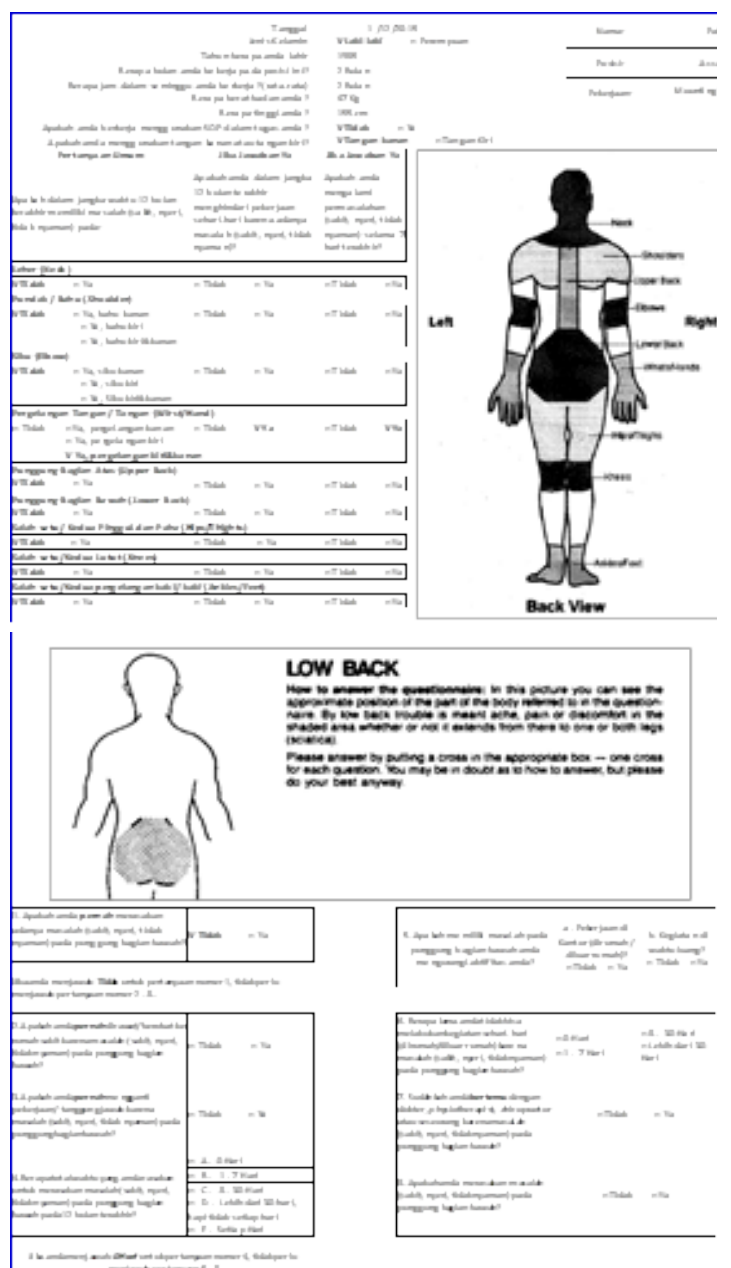

Gambar 5. Kuesioner nordik awal operator A

setiap kebutuhan pelanggan yang dapat mengarah pada desain produk (Gambar 6).

1. Mudah dioperasikan. Peralatan pendukung yang baru harus mudah dioperasikan sehingga operator tidak merasa kebingungan saat menggunakannya.

2. Mengurangi postur tubuh yang canggung (menggapai objek di lantai). Peralatan pendukung ini harus mampu mendekatkan objek ke area jangkauan operator dan menghindari postur membungkuk.

3. Aman dan nyaman digunakan oleh operator. Harus ada alat pengaman untuk menghindari operator dari cedera atau kecelakaan selama proses berlangsung.

4. Dapat digunakan untuk berbagai tipe dan ukuran ban. Peralatan pendukung ini harus fleksibel dan tidak hanya dikhususkan untuk ban tertentu, tetapi universal.

5. Ketinggian bisa disesuaikan. Karena masalah postur tubuh yang canggung 
adalah yang harus diatasi, mereka ingin perlengkapan pendukungnya bisa disesuaikan dari segi ketinggian. Operator dapat mengatur sendiri ketinggiannya.

6. Pekerjaan menjadi lebih efektif dan efisien dalam hal waktu. Sebelumnya pada proses awal terdapat beberapa tahapan dan gerakan untuk menyelesaikan proses pemasangan ban truk.

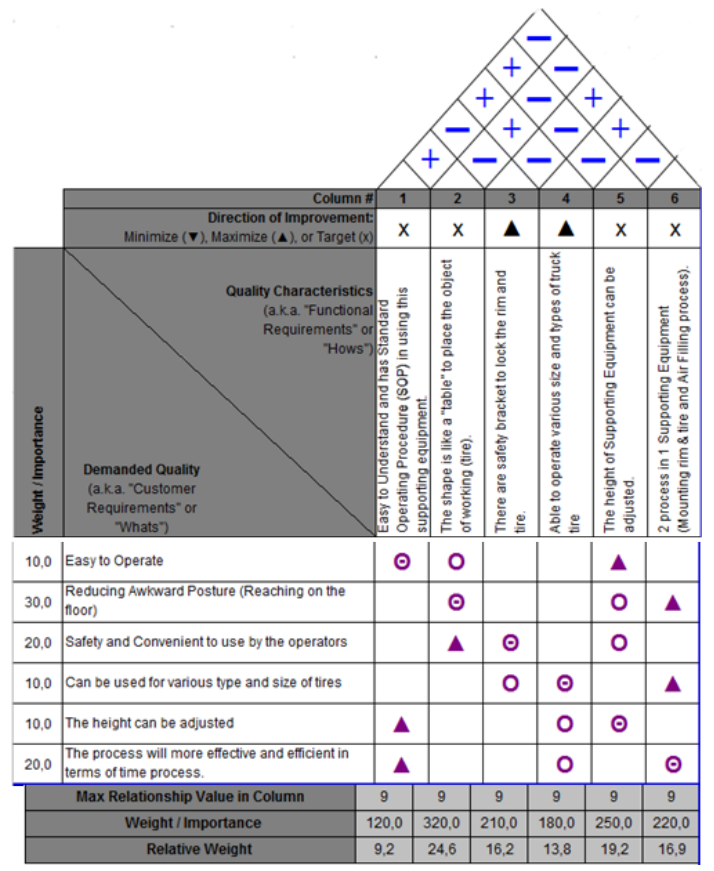

Gambar 6. QFD peralatan pendukung pemasangan ban truk

Karena desain produk alat bantu yang akan diaplikasikan pada peralatan pendukung harus memenuhi kebutuhan operator, maka ditemukan beberapa spesifikasi produk yang sesuai dengan yang harapan operator yang ditunjukkan pada Gambar 7 dan 8, yaitu:

1) Mudah dipahami dan memiliki Standard Operating Procedure (SOP) dalam menggunakan peralatan pendukung ini.

2) Bentuknya seperti "meja" untuk tempat benda kerja (ban).

3) Ada braket pengaman untuk mengunci pelek dan ban.

4) Mampu mengoperasikan berbagai ukuran dan tipe ban truk

5) Ketinggian peralatan pendukung dapat disesuaikan.

6) Satu peralatan pendukung dapat mendukung dua proses (pemasangan ban pada velg dan proses pengisian Udara).
Efesiensi dan low cost invenstment adalah hal yang sangat penting bagi perusahaan. Karena tempat dilakukan penelitian adalah produsen alat berat yang memproduksi trailer dan alat berat lainnya, maka di sini banyak bahan bekas yang sudah tidak digunakan lagi.
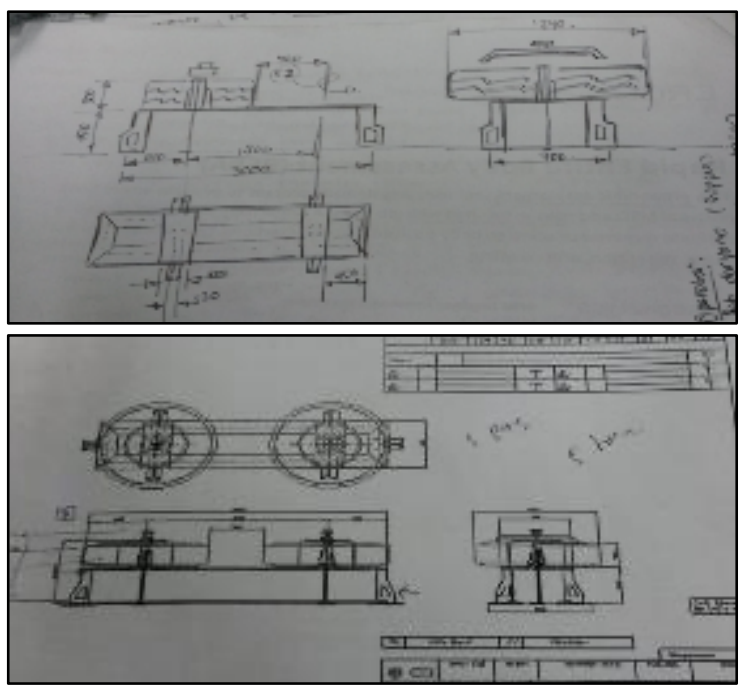

Gambar 7. Sketsa dan gambar akhir dari peratan pendukung
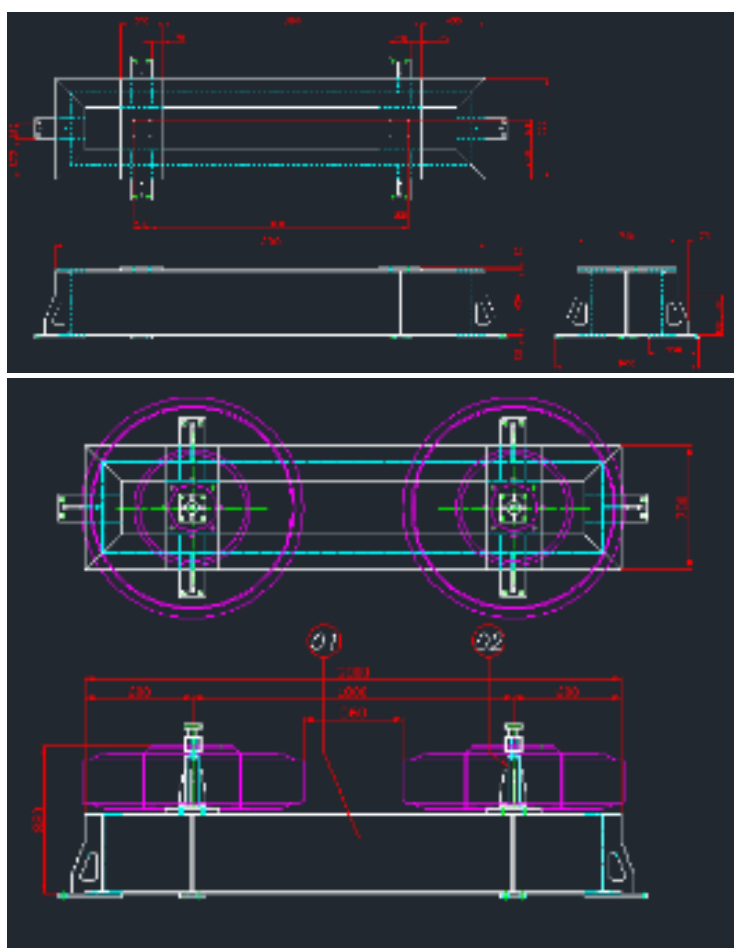

Gambar 8. Gambar lengkap peralatan pendukung

Berikut adalah daftar bahan yang digunakan untuk pembuatan alat penunjang ini dengan biaya yang ditunjukkan pada Tabel 2 :

a. I - Wide Flange $3000 \times 200 \times 450=201,8$

$\mathrm{Kg} \times 2$ pcs (Balok IWF untuk panjang $3 \mathrm{~m}$ ) 
b. I - Wide Flange $700 \times 200 \times 450=47 \mathrm{Kg} \mathrm{x}$ 2 pcs (Balok IWF untuk panjang $0.7 \mathrm{~m}$ )

c. $\quad \mathrm{T} 20 \times 300 \times 700=32,9 \mathrm{Kg} \times 2$ buah (Basis di tengah)

d. T20 $\times 150 \times 350=8,2 \mathrm{Kg} \times 6$ Pcs (Berbasis di lantai)

e. $\quad 20 \times 170 \times 435=7.0 \mathrm{Kg} \times 6$ Pcs

Tabel 2. Investasi dan biaya produksi dari peralatan pendukung

\begin{tabular}{|c|c|c|}
\hline No & Nama & Biaya (Rp) \\
\hline 1. & Material $^{*}$ & ${ }^{*} 9,700,000$ \\
\hline 2. & $\begin{array}{l}\text { Material proses produksi } \\
\text { seperti: pengelasan, } \\
\text { gerinda, dan lain-lain }\end{array}$ & 300,000 \\
\hline 3 & $\begin{array}{l}\text { Man power ( } 2 \text { orang, } 10 \\
\text { hari kerja) }\end{array}$ & $2,000,000$ \\
\hline & Biaya produksi total & $12,000,000$ \\
\hline & Investasi perusahaan & $2,300,000$ \\
\hline
\end{tabular}

Proses fabrikasi alat pendukung baru ini membutuhkan waktu 10 hari kerja dan 2 tenaga kerja. Proses fabrikasi meliputi, diantaranya proses pemotongan logam, proses pengelasan, proses gerinda, hingga proses pengecatan, sebagaimana diperlihatkan dalam Gambar 9.

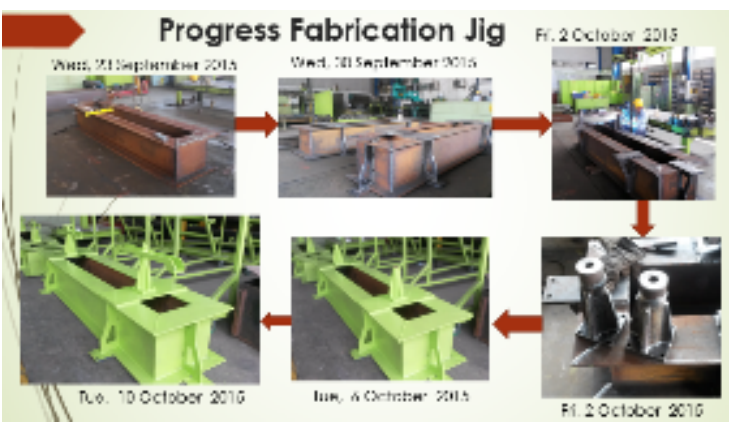

Gambar 9. Proses fabrikasi peralatan pendukung pemasangan ban truk

Secara keseluruhan, desain peralatan pendukung ini diperoleh dari pendekatan QFD yang bersumber pada $\mathrm{VoC}$ operator dan pengguna proses pemasangan ban truk. Panjang produk ini $3 \mathrm{~m}$, lebar $1,24 \mathrm{~m}$, dan tinggi $0,85 \mathrm{~m}$. Bobot produk ini adalah $296.9 \mathrm{Kg}$ tanpa ban dan pelek. Bobot pelek ban truk sendiri 75 $\mathrm{Kg}$ dan bobot ban $90 \mathrm{Kg}$, jadi total bobot ban truk siap pakai adalah $165 \mathrm{Kg}$. Jika ban truk sedang dalam proses di peralatan pendukung ini maka berat totalnya menjadi $461,9 \mathrm{Kg}$. Proses pemasangan ban truk setelah menggunakan alat bantu ini dapat ditunjukkan pada Gambar 10.

\section{Analisis Postur Tubuh REBA - Final}

Skor akhir REBA setelah proses perbaikan pemasangan ban truk menunjukkan skor 7 . Skor 7 menurut Lembar Kerja Penilaian Karyawan REBA oleh Ergonomics Plus menunjukkan angka ini termasuk dalam risiko medium risk, further investigation, change soon. Situasi setelah perbaikan digambarkan pada Gambar 11.

Secara umum analisis yang dihasilkan oleh REBA dalam proses pemasangan ban truk dikarenakan material handling yang dilakukan secara manual oleh operator, meskipun posturnya sudah tidak janggal lagi, penanganan ban dengan menggunakan tangan mengalami kendala di skor kopling dan berat benda $90 \mathrm{Kg}$ membuat prosesnya menjadi sulit. Ada beberapa poin yang harus dievaluasi:

- Berat objek. Operator menggunakan tenaga yang sangat besar untuk mengangkat dan menangani ban truk mengingat ukuran ban dengan diameter $120 \mathrm{~cm}$ tinggi $30 \mathrm{~cm}$ dan berat $90 \mathrm{Kg}$. Dapat dipahami bahwa proses ini membutuhkan tenaga lebih dari operator untuk menanganinya.

- Penanganan Tangan / Pergelangan Tangan. Skor kopling menunjukkan angka 3 karena tangan operator tidak dirancang untuk menangani benda bulat dan bundar seperti ban dalam waktu yang cukup lama (perlu waktu 1 menit untuk menyesuaikan).

\section{Analisis Kondisi Tubuh Kuisioner Nordik - Final}

Dapat terlihat dari 9 bagian tubuh yang dinilai pada Nordic Questionnaire Gambar 12, hanya tertinggal satu bagian tubuh $(11,11 \%)$ yang menunjukkan ketidaknyamanan pada

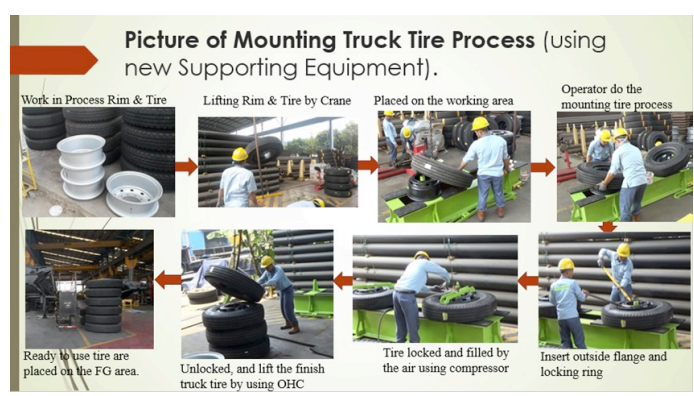

Gambar 10. Gambaran proses pemasangan ban truk menggunakan alat pendukung yang sudah dibuat 
Tabel 3. Perbandingan kondisi awal dan setelah perbaikan

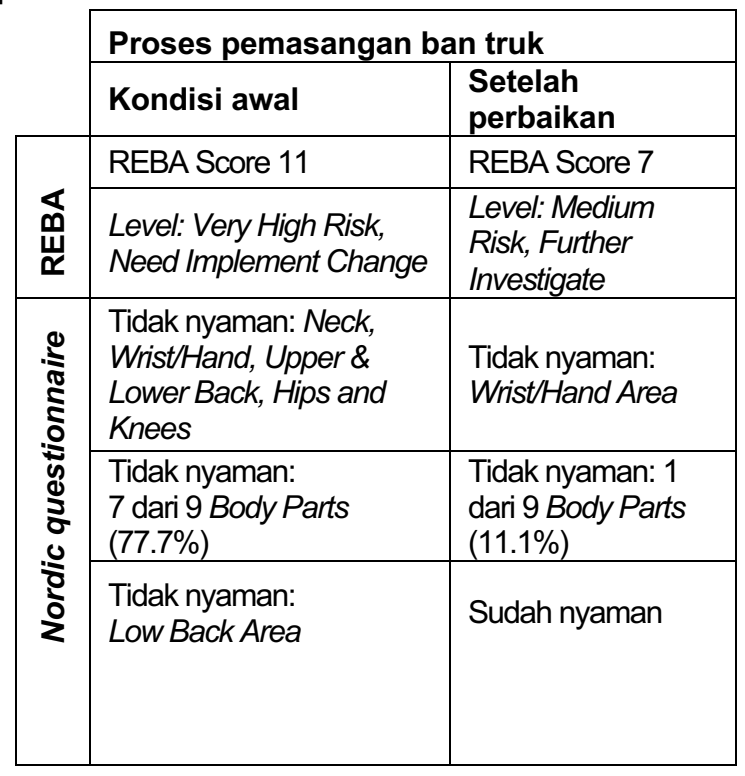

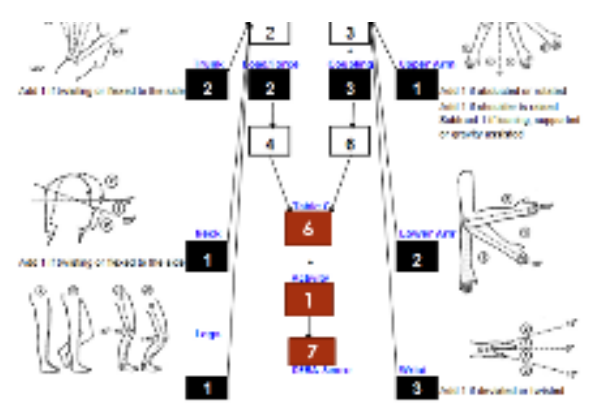

Gambar 11. REBA setelah perbaikan

area pergelangan tangan / tangan. Ini bisa dipahami dan tidak bisa dihindari karena penanganan material secara manual oleh operator.

Dari hasil Nordic Questionnaire secara spesifik di area low back, penggunaan peralatan pendukung baru telah direspon dengan sangat baik dalam hal mengatasi masalah ketidaknyamanan yang dialami oleh operator pemasangan ban truk. Hal ini dibuktikan dengan hasil kuesioner Nordik Gambar 12, bahwa operator tidak lagi menderita ketidaknyamanan di area Low Back.

\section{Analisis sebelum dan sesudah perbaikan}

Pada Tabel 3 dijelaskan seberapa besar perbaikan yang diberikan oleh peralatan pendukung baru ini. Dari analisis REBA, skor awal proses pemasangan ban truk adalah 11 dan dikategorikan sebagai risiko sangat tinggi, sehingga perlu dilakukan perbaikan. Level ini dapat dianggap sebagai situasi yang mendesak dan perlu segera diperbaiki untuk pulih dari postur yang canggung ini. Perbaikan yang dilakukan oleh perangkat pendukung baru ini adalah menurunkan level REBA hingga ke angka 7 yang berada pada level risiko sedang dan perlu investigasi lebih lanjut.

Dari kuesioner Nordik, kuesioner nordik awal menunjukkan bahwa tubuh operator merasakan ketidaknyamanan pada 7 bagian tubuh dari 9 bagian tubuh yaitu; leher, pundak/ bahu, pergelangan tangan/ tangan, punggung atas dan bawah, pinggul, dan lutut. Setelah itu fokus kuesioner Nordik pada daerah punggung bawah menunjukkan bahwa proses awal mengakibatkan ketidaknyamanan di daerah punggung bawah. Setelah dilakukan perbaikan, tingkat ketidaknyamanan berkurang dari 7 bagian tubuh menjadi hanya 1 bagian tubuh yang tersisa tidak nyaman (pergelangan tangan / tangan). Untuk fokus area low back,
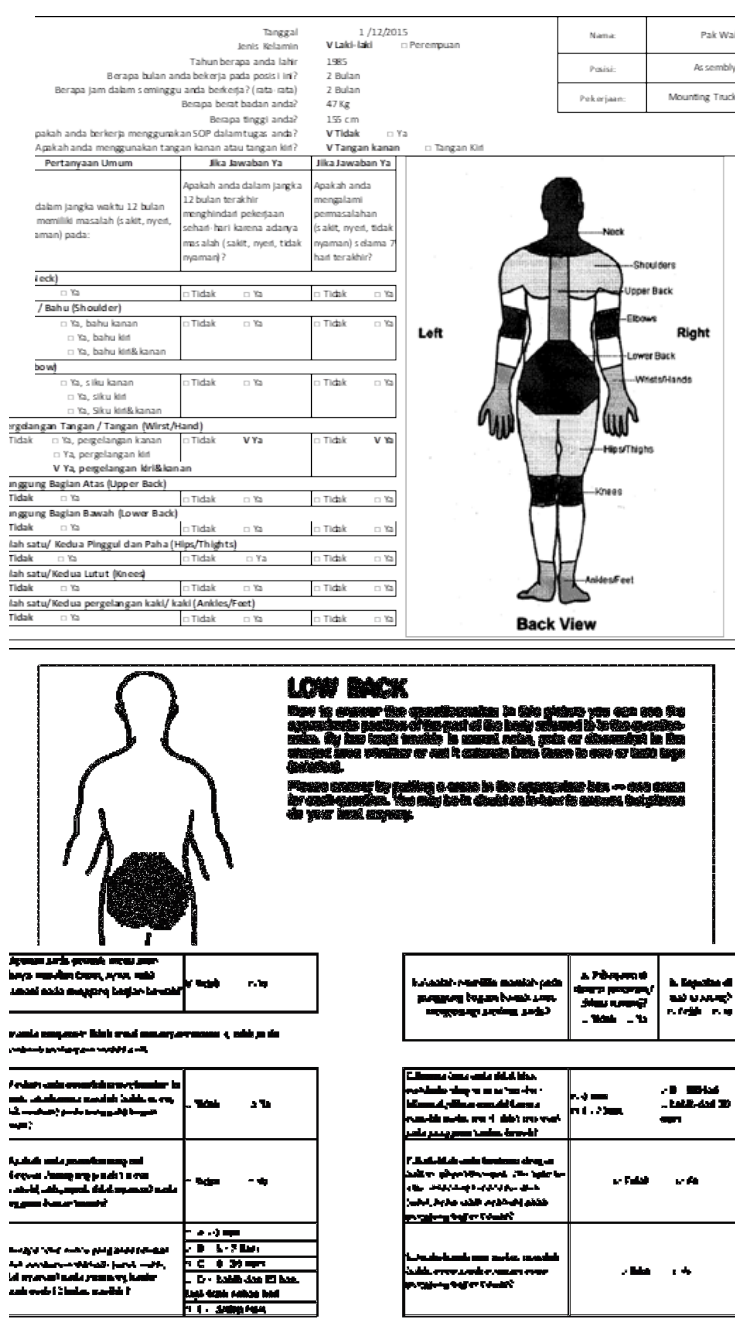

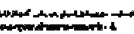

Gambar 12. Nordic questionnaire of operator, A 
penyempurnaan sudah membawa hasil yang signifikan hingga tidak ada ketidaknyamanan yang dirasakan operator pemasangan ban truk pada area tersebut

Tersedianya alat bantu ini mendapatkan respon yang sangat baik dari operator karena desainnya sesuai dengan harapan mereka sebagaimana teridentifikasi dalam QFD sehingga sangat membantu memudahkan pekerjaan mereka. Kemudian, sesuai dengan permintaan operator, adanya panduan atau SOP menjadikan operator tidak membutuhkan waktu yang terlalu lama untuk menguasai penggunaan alat bantu tersebut, tentu setelah terlebih dahulu diberikan sedikit pelatihan.

Secara umum, ketersediaan alat bantu handling sangat penting apalagi jika materialnya berukuran besar dan berat. Keberadaan alat bantu ini memang kadang suka terabaikan oleh perusahaan karena menganggap itu menjadi tambahan investasi. Namun pada penelitian ini dapat ditunjukkan bahwa investasi untuk membangun alat bantu tidaklah harus mahal jika perusahaan cukup kreatif untuk memanfaatkan resources yang mereka memiliki, bahkan dalam penelitian ini dapat ditunjukkan bahwa material yang digunakan untuk membuat handling tersebut cukup memanfaatkan material sisa yang sudah terbuang atau tidak digunakan lagi. Namun dalam desain produknya perlu juga memperhatikan masukan dari para operator.

Karena tingkat urgensi yang tinggi dari siapnya alat bantu ini untuk digunakan dan juga terbatasnya waktu penelitian, maka perhitungan beban yang diterima (compressive force and shear force) sebagaimana dijelaskan dalam (Lavender et al., 2020) dan (Xiang et al., 2021), (Theopilus et al., 2018) baik sebelum dan setelah perbaikan tidak dilakukan. Namun dengan melakukan perbandingan secara visual kondisi awal yang ditunjukkan Gambar 3 dan 4 kemudian kondisi setelah menggunakan alat bantu yang ditunjukkan prosesnya dalam Gambar 10, maka dapat terlihat bahwa beban kerja menjadi berkurang. Sebagaimana telah dijelaskan dibagian awal, bobot produk handling ini adalah $296.9 \mathrm{Kg}$ tanpa ban dan pelek. Bobot pelek ban truk sendiri $75 \mathrm{Kg}$ dan bobot ban $90 \mathrm{Kg}$, jadi total bobot ban truk siap pakai adalah $165 \mathrm{Kg}$. Sehingga beban sebesar $165 \mathrm{~kg}$ yang tadinya harus di handle langsung tanpa alat bantu menjadi berkurang karena adanya alat bantu ini. Hal ini juga di respon positif oleh para operator.

\section{Kesimpulan}

Setelah dilakukan perbaikan berdasarkan hasil awal REBA dan Nordik sebagai bukti di awal dan dilanjutkan dengan perancangan perangkat pendukung dengan menggunakan pendekatan QFD, maka tujuan dari penelitian ini sudah didapatkan. Peningkatan yang ditunjukkan oleh hasil REBA dan Nordik menjadi bukti bahwa peralatan pendukung baru ini telah bekerja dengan baik. Berdasarkan perbandingan skor, terlihat bahwa proses ini yang awalnya berada pada level risiko sangat tinggi kini menjadi risiko sedang pada skor REBA. Dari kondisi badan operator juga terasa lebih baik setelah hasil perbaikan, dimana awalnya ada 7 bagian tubuh yang merasa tidak nyaman sekarang hanya 1 bagian tubuh yang masih merasakan ketidaknyamanan dan masih dalam batas wajar.

Secara keseluruhan, awalnya proses pemasangan ban truk tidak ergonomis, hal ini didukung oleh hasil analisis postur tubuh dengan pendekatan REBA. Kini peralatan pendukung baru ini akan menjadi jawaban yang tepat untuk mengatasi masalah pada area ban truk mounting dan akan menghindari operator merasakan gejala Cumulative Trauma Disorders (CTDs) terutama pada area low back.

\section{Daftar Pustaka}

Berlin, C., Adams, C., \& Chalmers University of Technology, SE. (2017). Production Ergonomics: Designing Work Systems to Support Optimal Human Performance. Ubiquity Press.

Bintang, A. N., \& Dewi, S. K. (2017). Analisa Postur Kerja Menggunakan Metode OWAS dan RULA. Jurnal Teknik Industri, 18(1), 43.

Christy, D. V. (2019). Ergonomics and Employee Engagement. International Journal of Mechanical Engineering and Technology (IJMET), 10(2), 5.

Crawford, J. O. (2007). The Nordic Musculoskeletal Questionnaire. Occupational Medicine, 57(4), 300-301.

Fitriani, A., \& Purnomo, H. (2018). Perancangan dan Pengembangan Bed Shower Menggunakan Metode Quality Function Deployment (QFD) Berdasarkan Prinsip 
Ergonomi. Jurnal Sistem dan Manajemen Industri, 2(2), 85.

Haripurna, A., \& Purnomo, H. (2017). Desain Perancangan Alat Penyaring Dalam Proses Pembuatan Tahu Dengan Metode Macro Ergonomic Analysis and Design (MEAD). Jurnal Ilmiah Teknik Industri, 16(1), 22.

Hignett, S., \& McAtamney, L. (2000). Rapid Entire Body Assessment (REBA). Applied Ergonomics, 31(2), 201-205.

Kosasih, R. R., Martini, S., \& Rahayu, M. (2019). Perancangan Alat Bantu untuk Liquid Container Berdasarkan Penilaian Rapid Entire Body Assessment dan Washington State Checklist. Jurnal Sistem dan Manajemen Industri, 3(1), 10.

Lavender, S. A., Sommerich, C. M., Bigelow, S., Weston, E. B., Seagren, K., Pay, N. A., Sillars, D., Ramachandran, V., Sun, C., Xu, Y., \& Marras, W. S. (2020). A biomechanical evaluation of potential ergonomic solutions for use by firefighter and EMS providers when lifting heavy patients in their homes. Applied Ergonomics, 82, 102910. https://doi.org/10.1016/j.apergo.2019.10291 0

López-Aragón, L., López-Liria, R., CallejónFerre, Á.-J., \& Gómez-Galán, M. (2017). Applications of the Standardized Nordic Questionnaire: A Review. Sustainability, 9(9), 1514.
Middlesworth, M. (2014). A Step-by-step Guide, Rapid Entire Body Assessment (REBA). Ergonomics Plus Inc.

Sari, F. P., Suhardi, B., \& Astuti, R. D. (2017). Penilaian Postur Kerja di Area Konstruksi CV. Valasindo dengan Metode Quick Exposure Check. PERFORMA: Media IImiah Teknik Industri, 16(2). https://doi.org/10.20961/performa.16.2.1698 0

Shorrock, S. T., \& Williams, C. A. (2016). Human factors and ergonomics methods in practice: Three fundamental constraints. Theoretical Issues in Ergonomics Science, 17(5-6), 468-482.

Theopilus, Y., Jonathan, W., \& Gustin, Y. (2018). Pengembangan Alat Bantu Material handling untuk Meminimasi Beban Kerja Operator Produksi Crank Case di PT.X. Jurnal Rekayasa Sistem Industri, 7(2), 85.

Wahyuniardi, R., \& Reyhanandar, D. M. (2018). Penilaian Postur Operator Dan Perbaikan Sistem Kerja Dengan Metode Rula Dan Reba (studi Kasus). J@ti Undip: Jurnal Teknik Industri, 13(1), 45.

Xiang, X., Yamada, Y., Akiyama, Y., Tao, Z., \& Kudo, N. (2021). Validation of Lumbar Compressive Force Simulation in Forward Flexion Condition. Applied Sciences, 11(2), 726. 
DOI: https://doi.org/10.26593/jrsi.v10i2.4397.161-172

Halaman ini sengaja dikosongkan.

This page is intentionally left blank. 